\title{
The Effect of Land-Use Intensity on Surface Temperature in the Dongting Lake Area, China
}

\author{
Wenmin Hu, ${ }^{1}$ Weijun $\mathrm{Zhou}^{1}$ and Hongshi $\mathrm{He}^{2}$ \\ ${ }^{1}$ College of Resources and Environment, Hunan Agricultural University, Changsha 410128, China \\ ${ }^{2}$ Institute of Applied Ecology, Chinese Academy of Sciences, Shenyang 110016, China \\ Correspondence should be addressed to Wenmin Hu; wenmin115@163.com
}

Received 27 August 2014; Revised 30 October 2014; Accepted 8 December 2014

Academic Editor: Jinwei Dong

Copyright (C) 2015 Wenmin Hu et al. This is an open access article distributed under the Creative Commons Attribution License, which permits unrestricted use, distribution, and reproduction in any medium, provided the original work is properly cited.

\begin{abstract}
Land use and its environmental effects can be quantitatively expressed with land-use intensity. In this study, a land-use intensity metric was improved using a geographic mapping method. The relationships between observed rapid changes in land use and temperature in the Dongting Lake area from 2001 to 2010 were examined. The results revealed the following features: (1) The temperature increased when the land-use intensity increased via a hierarchical transition owing to grass and forest land reductions of $26.25 \%$ and $11.74 \%$, respectively; built-up land increased by $48.45 \%$. (2) The temperature increase was driven more by the external environment than by land-use intensity changes. Human activities produced larger effects in the western region than in the eastern or central region of the study area, according to the observed variations in the centres of gravity for temperature and land-use intensity. (3) The temperature response to land-use intensity changes was more sensitive in low-altitude areas than in high-altitude areas; the response presented a north-south gradient, possibly due to socioeconomic and urbanisation differences.
\end{abstract}

\section{Introduction}

With rapid social and economic development, the influence of human activities on the land surface temperature (LST) has intensified. Land-use intensity can convey the intensity of human activities and can provide a basis for discussing the relationship between land-use and environmental changes [1]. Changes in land-use intensity can be regarded as an extension of land-use/cover changes (LUCC) [2]. These changes are influenced by not only land cover but also policy measures [3], such as adjusting the structure of land use [4], regulating urban expansion, or optimising economic structures [5]. These changes impact environmental factors, such as the LST [6]. Therefore, the surface temperature could be affected by the variation in and intensity of land use.

Presently, the relationship between surface temperature and land-use intensity is difficult to determine because the quantitative expression for land-use intensity is complicated. Many studies have applied the land-use area [7], the landscape index [8], or particular quality control indexes, such as the intensity of a water supply and drainage, the amount of fertilisation, water consumption, or energy consumption [9-11]; however, these metrics are unable to embody the impacts of human activities on the land-use environment. Our study defines land-use intensity according to the "Study on China's Land Use of Temporal and Spatial Information on Remote Sensing" and seeks to improve the quantitative expression of land-use intensity using a GIS cartographic method. This new method might more reasonably explain the relationship between changes in land-use intensity and surface temperature.

Our study period was from 2001 to 2011 when the global temperature drastically changed $[12,13]$. Many studies suggest that this period is indicative of a temperature spike. Foster and Rahmstorf [14] considered this period as having the most rapid global temperature increase. Solomon and Newman [15] emphasised that the thermal and atmospheric circulations in this period accelerated oceanic warming. Fall et al. [16] found that land-use and cover changes during the period resulted in greater warming compared with greenhouse gases. In addition, the study area around Dongting Lake, which is China's second largest interior lake, is a centre 


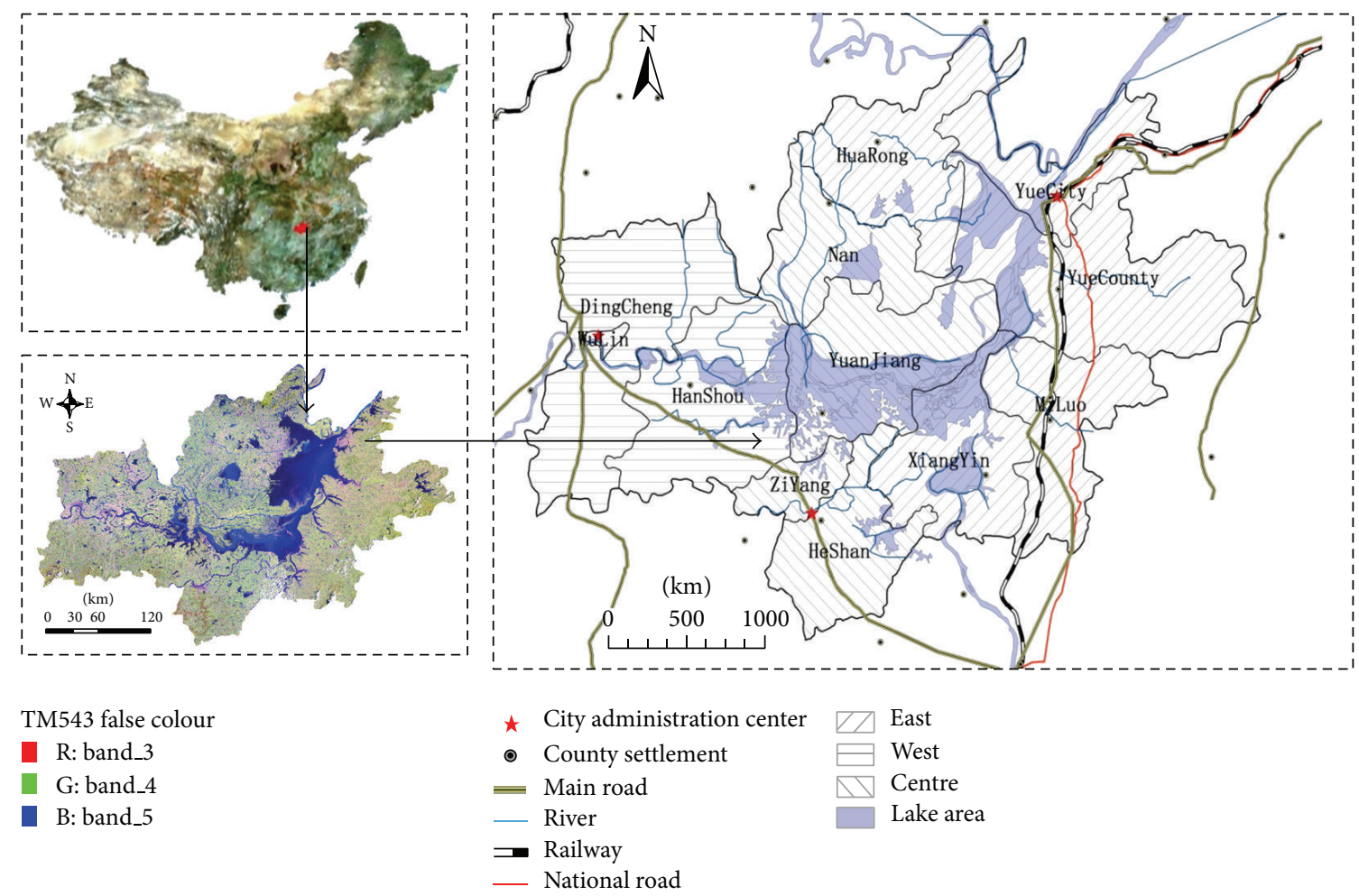

FIgure 1: The location of the study area.

for the development of the national agricultural economy. Because of the influence of economic development and social activities, the surface temperatures were strongly affected by land-use changes.

Therefore, our research objectives were as follows: to determine the spatiotemporal differences between surface temperature changes and land-use intensity in the Dongting Lake area, to identify the intrinsic link between the landscape and gravitational and zonal changes in the macroenvironment, and to reveal the relationship between land-use intensity and land surface temperature from a geographical perspective. The results could lead to improvements in the ecological environment and provide a reference for rational land-use policy in the lake district.

\section{Material and Methods}

2.1. Study Area. The Dongting Lake District $\left(28^{\circ} 03^{\prime}-\right.$ $30^{\circ} 20^{\prime} \mathrm{N}, 110^{\circ} 40^{\prime}-113^{\circ} 30^{\prime} \mathrm{E}$ ), which is located in central China (Figure 1), encompasses approximately $21,000 \mathrm{~km}^{2}$. Dongting is the second largest freshwater lake in China and is listed as one of the world's most substantial wetlands. The lake is divided into eastern, central, and western areas that are governed by three cities (Yueyang, Yiyang, and Changde, resp.). The average annual temperature is $16.6-17.6^{\circ} \mathrm{C}$; the temperature is approximately $4.5^{\circ} \mathrm{C}$ in January and $30^{\circ} \mathrm{C}$ in July. The average annual precipitation is $1,303 \mathrm{~mm}$. Approximately 16.63 million people live in the district $(23.5 \%$ of the population of Hunan Province). The main landforms are plains and lakes that have abundant natural resources.
The Dongting Lake District is an important economic production area in China. The economy has rapidly developed in recent years. In 2000, the urbanisation rate was $19 \%$, and the regional GDP was 14.5 billion dollars. However, in 2011, the urbanisation rate increased to $38 \%$, and the regional GDP was 56.3 billion dollar. The ratio of the industry, agriculture, and service sectors was $19: 45: 36$. Agriculture has always played an important role in the district's economy.

2.2. Data Sources and Preprocessing. The land-use data were derived from TM/ETM+ images of LANDSAT5/7, which were downloaded from China's International Scientific Data Service Platform (http://www.gscloud.cn/). The data were obtained for the summers of 2001 and 2011, which correspond to the climate normal period. The images were preprocessed with radiation correction, geometric correction, and stripe elimination. According to the State-Level Land-Use and Coverage Classification System [17], the land was classified with a hierarchical decision tree using the supervised classification method [18]. Initially, the land was classified into thirteen land-use types: dry land, paddy field, high-coverage forested land, low-coverage forested land, high-coverage grassland, moderate-coverage grassland, low-coverage grassland, lakes, rivers, reservoirs, urban land, rural residential land, sand, and other lands. Then, the data were consolidated into six first-class types (Level II to Level I): cultivated land, forested land, built-up land, grassland, water body, and unused land (Table 1). The classification-precision assessment reached 83.5\% using a land-use status map from 2006. 


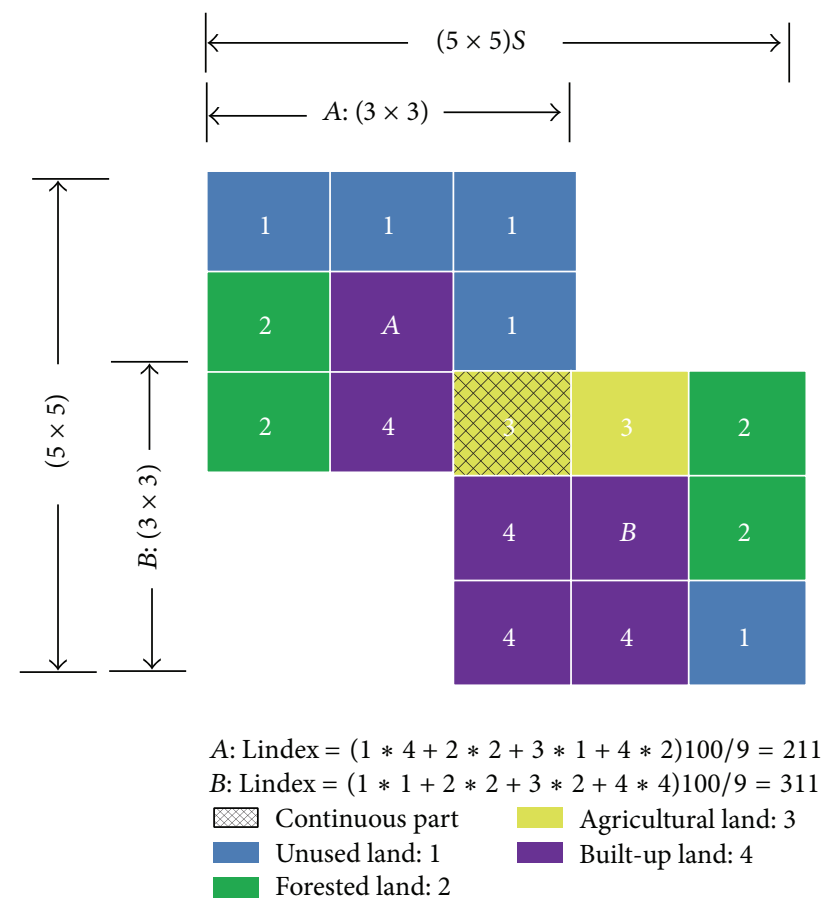

FIGURE 2: Spatial information of land-use intensity.

2.3. Optimisation of the Land-Use Intensity Expression. Landuse intensity varies according to the land-use type. Moreover, the consensus [19] is that built-up land has the highest intensity, followed by forested land, grassland, water bodies, and unused land. Therefore, the land-use intensity was classified into four grades, and each grade was assigned a value (Table 2). The land-use grades are the four ideal states in Table 1; however, the four states are actually unequally mixed within the same area. Using the grades, the land-use intensity forms a continuous-distribution composite index that ranges from 1 to 4 . For the convenience of geographical calculations, the values were multiplied by 100 ; therefore, the land-use intensity is equivalent to the Weaver index.

The expression of land-use intensity is as shown in Table 2:

$$
\text { Lindex }=100 \times \sum_{i=1}^{n} A_{i} \times C_{i} .
$$

Lindex is the comprehensive index of land-use intensity for which Lindex $\in[100,400], A_{i}$ is the classification index of land use at the $i$ th grade, $C_{i}$ is the percentage of land-use intensity at the $i$ th grade, and $n$ is the classification number of the land-use intensity, $n=4$.

An expression based on geographical radiative units (Figure 2) was developed. The weight coefficients mainly radiate outward from the basic units of $A$ and $B$. The radius is one unit, and $A$ and $B$ represent the average land-use intensity of the region $(3 \times 3)$. The shaded areas are the mutual units connecting $A$ and $B$. When $A$ and $B$ are calculated, their mutual units should be calculated repeatedly. Therefore, the average land-use intensity of the radiated areas in $A$ and $B$ was 211 and 311, respectively. This expression shows
TABLE 1: Land-use/cover classification in the Dongting Lake area.

\begin{tabular}{lc}
\hline Level I categories & Level II categories \\
\hline Cultivated land & $\begin{array}{c}\text { Dry land } \\
\text { Paddy field }\end{array}$ \\
\hline Forested land & $\begin{array}{c}\text { High-coverage forested land } \\
\text { Low-coverage forested land }\end{array}$ \\
\hline Grassland & $\begin{array}{c}\text { High-coverage grassland } \\
\text { Moderate-coverage grassland } \\
\text { Low-coverage grassland }\end{array}$ \\
\hline Water body & $\begin{array}{c}\text { Lakes } \\
\text { Rivers }\end{array}$ \\
\hline Built-up land & Reservoirs \\
\hline Unused land & Urban land \\
& Rural residential land \\
\hline
\end{tabular}

the influence of the surrounding land types and the continuity in geographical space; therefore, the expression is more scientific in practice.

This method can effectively express the continuous characteristics of land-use intensity and the extent of land-use aggregation. The units were not subject to administrative partitions and were related to only the grid granularity (resolution) and scale (search radius). A higher unit resolution yields a more accurate expression. The unit value could also reflect the characteristics of the landscape. For example, a value within $[300,400]$ indicates that built-up land provided the greatest contribution, so built-up land was the dominant land-use type. In this research, $30 \mathrm{~m}$ resolution remotesensing data were adopted; the radiative radius was 15 units or $930 \mathrm{~m} \times 930 \mathrm{~m}$. The value of each unit represented the average land-use intensity within an area of $8.4 \mathrm{hm}^{2}$. The total number of units was 5,877 .

2.4. Land Surface Temperature Inversion. Table 3 showed the average surface temperature distribution in Dongting Lake, and the data in Table 3 was obtained from the China Statistical Yearbook. July, August, and September, which are the warmest months (summer) in the lake area, are chosen to facilitate intraseasonal comparisons.

The LSTs in July, August, and September of 2001 and 2011 in the Dongting Lake District were derived from NASA MODIS data (US). The image data were preprocessed with atmospheric corrections, radiometric calibrations, graphic clipping, and geometric corrections. The LST was calculated using the split-window algorithm (Figure 4) [20]. The process is as follows:

$$
\mathrm{TS}=A_{0}+A_{1} T_{31}-A_{2} T_{32},
$$

where TS is the surface temperature $(\mathrm{K}), T_{31}$ and $T_{32}$ are the satellite radiances of MODIS in the 31st and 32nd spectral 
TABLE 2: Land-use intensity grade.

\begin{tabular}{lcccc}
\hline Land-use type & Unused land-use grade & $\begin{array}{c}\text { Forested land, grassland, } \\
\text { water-body use grade }\end{array}$ & $\begin{array}{c}\text { Agricultural land-use } \\
\text { grade }\end{array}$ & Urban land-use grade \\
\hline Grading index & 1 & 2 & 3 & 4 \\
\hline
\end{tabular}

TABLE 3: Average surface temperature distribution in Dongting Lake in 2001 and 2011 (unit: ${ }^{\circ} \mathrm{C}$ ).

\begin{tabular}{ccccccc}
\hline Year & May & June & August & September & September & October \\
\hline 2001 & 23.0 & 24.9 & 29.2 & 27.3 & 26.1 & 18.9 \\
2011 & 21.8 & 24.2 & 30.5 & 28.8 & 25.3 & 17.5 \\
\hline
\end{tabular}

bands, respectively, and $A_{0}, A_{1}$, and $A_{2}$ are the split-window parameters, which are defined as follows:

$$
\begin{gathered}
A_{0}=E_{1} a_{31}-E_{2} a_{32}, \\
A_{1}=1+A+E_{1} b_{31}, \\
A_{2}=A+E_{2} b_{32},
\end{gathered}
$$

where $a_{31}, b_{31}, a_{32}$, and $b_{32}$ are constants. Within the surface temperature range of $0-50^{\circ} \mathrm{C}$, these constants are $a_{31}=$ $-64.60363, b_{31}=0.440817, a_{32}=-68.72575$, and $b_{32}=$ 0.473453 . The intermediate parameters of the abovementioned equations are calculated as follows:

$$
\begin{gathered}
A=\frac{D_{31}}{E_{0}} \\
E_{1}=\frac{D_{32}\left(1-C_{31}-D_{31}\right)}{E_{0}} \\
E_{2}=\frac{D_{31}\left(1-C_{32}-D_{32}\right)}{E_{0}} \\
E_{0}=D_{32} C_{31}-D_{31} C_{32} \\
C_{i}=\varepsilon \zeta_{i}(\theta) \\
D_{i}=\left[1-\zeta_{i}(\theta)\right]\left[1+\left(1-\varepsilon_{i}\right) \zeta_{i}(\theta)\right],
\end{gathered}
$$

where $i$ is the spectral band of MODIS $i=31$ or $32, \zeta_{i}(\theta)$ is the atmospheric transmissivity when the visual angle is $\theta$, and $C$ is Earth's surface emissivity in spectral band $i$. Finally, the average monthly temperature was consolidated according to the inversion result. The average temperatures in the summers of 2001 and 2011 were obtained. The precision test of the measured temperatures from the station in 2011 indicated that the standard error of the inversion precision was $0.25^{\circ} \mathrm{C}$, which meets the general requirement.

2.5. Centre of Gravity Model. The relationship between the variation in the land-use and temperature centre of gravity was investigated using the centre of gravity model. This model, which has been widely applied to analyse correlations and extent of influence [21], is expressed as follows:

$$
\begin{aligned}
& x=\frac{\sum_{i=1}^{n} x_{i} \times M_{i}}{\sum_{i=1}^{n} M_{i}}, \\
& y=\frac{\sum_{i=1}^{n} y_{i} \times M_{i}}{\sum_{i=1}^{n} M_{i}},
\end{aligned}
$$

where $x$ and $y$ are the centres of gravity of particular attributes in a region, $x$ is the longitude, $y$ is the latitude, $x_{i}$ and $y_{i}$ are the central longitude and latitude of the $i$ th unit, respectively, and $M_{i}$ is a particular attribute in the unit. In this study, the $M_{i}$ attributes were land-use intensity or temperature. The variation in the centre of gravity of attributes was calculated for the eastern, middle, and western areas of the Dongting Lake District:

$$
D_{W-j}=K \times\left[\left(x_{w}-x_{j}\right)^{2}+\left(y_{w}-y_{j}\right)^{2}\right]^{1 / 2}
$$

where $D_{w-j}$ represents the distance of the variation in the centre of gravity in different years, where $w$ represents a previous time and $j$ represents a later time, $\left(x_{w}, y_{w}\right)$ and $\left(x_{j}, y_{j}\right)$ represent the geographic position of the centre of gravity of a particular attribute at times $w$ and $j$, respectively, or the longitude and latitude of the centre of gravity in the region, and $K$ is a constant $(111.111 \mathrm{~km})$ for converting the longitude and latitude of the plan range.

\section{Results and Discussion}

3.1. Characteristics of Temperature Changes and Land-Use Intensity Changes. Figure 3 presents the results of the landuse classification and intensity expression in 2001 and 2011. Built-up land increased gradually, whereas forested land decreased due to a transition to agricultural and built-up land. The value of the land-use intensity in the Dongting Lake District varied between 100 and 400. A comparison of the land-use classification and intensity revealed that the land-use intensity varied with the land-use type, which was manifested as a continuous transitional feature. The colour gradually darkened from the water to the cultivated land and built-up land. Moreover, the land-use intensities were higher in locations close to urban centres (Figure 3). Therefore, the land-use intensity gradually increased towards urban centres, as represented by the scattered pattern from the urban centre to the suburbs. Additionally, the rapid urbanisation of the region is consistent with human activities.

Figure 4 displays the LST distribution in the summers of 2001 and 2011. High temperatures mainly occurred in urban centres, that is, the heat island effect. The regional average temperature exhibited an increase over the past decade; 


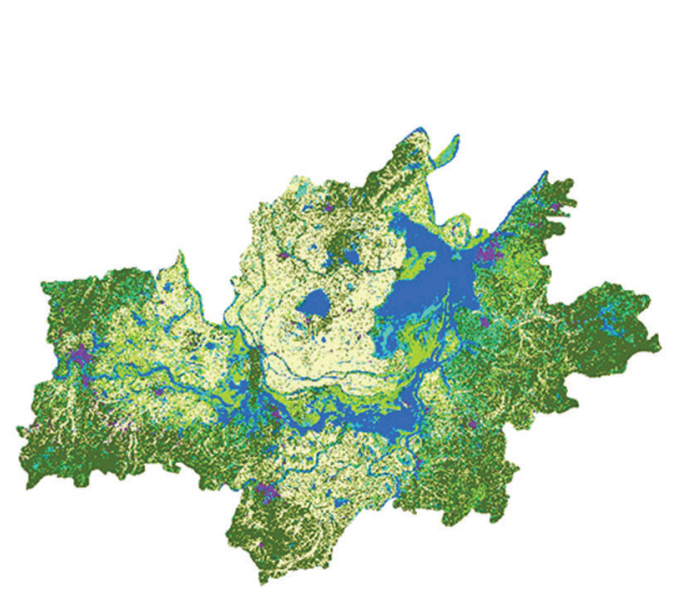

2001 land-use classification

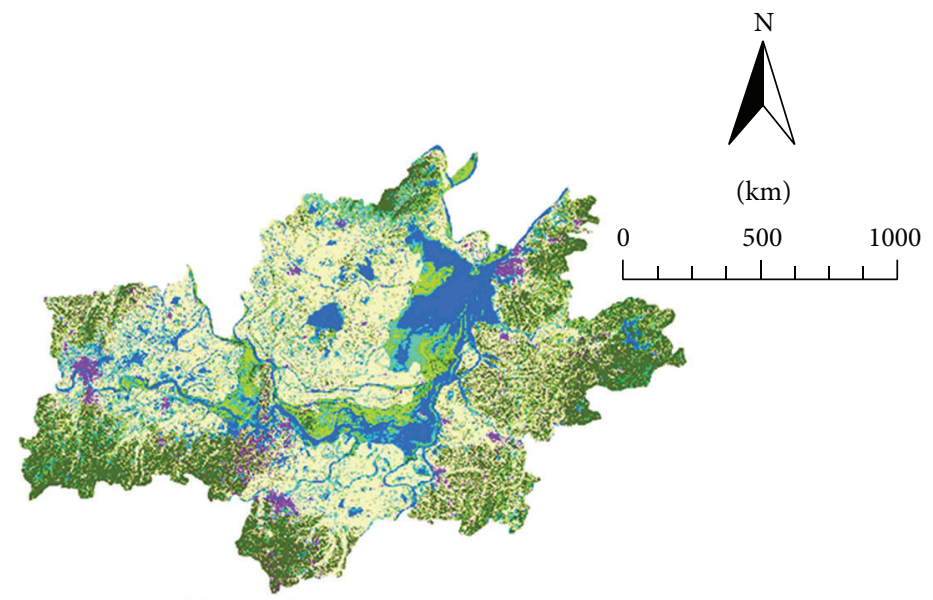

2011 land-use classification

$$
\begin{aligned}
& \text { Land-use class } \\
& \square \text { Built-up land } \quad \square \text { Grass land } \\
& \square \text { Unused land } \quad \square \text { Forested land } \\
& \square \text { Cultivated land } \quad \square \text { Water body }
\end{aligned}
$$$$
\text { Land-use class }
$$$$
\begin{array}{ll}
\square \text { Built-up land } & \text { Grass land } \\
\square \text { Unused land } & \text { Forested land } \\
\text { Cultivated land } & \square \text { Water body }
\end{array}
$$

Land-use intensity index
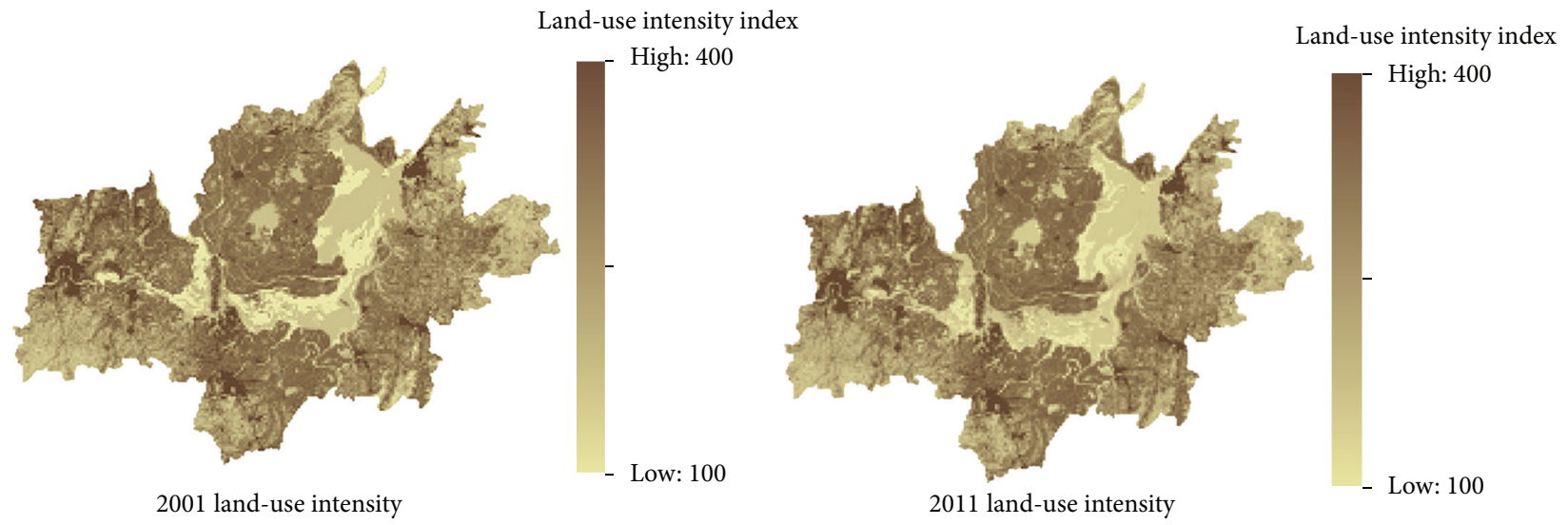

FIGURE 3: Spatial expression of the land-use classification and land-use intensity in 2001 and 2011.

the LST ranged from $-0.458^{\circ} \mathrm{C}$ to $1.421^{\circ} \mathrm{C}$. The temperature rise was higher in the south. The minimum, maximum, and average temperatures were, respectively, $29.411^{\circ} \mathrm{C}, 30.602^{\circ} \mathrm{C}$, and $30.048^{\circ} \mathrm{C}$ in 2001 and $29.849^{\circ} \mathrm{C}, 30.983^{\circ} \mathrm{C}$, and $30.422^{\circ} \mathrm{C}$ in 2011 (Figure 5). Over the ten years, the average temperature increased $0.374^{\circ} \mathrm{C} / 10 \mathrm{a}$ ( $10 \mathrm{a}$ indicates 10 years), and the maximum and minimum temperatures increased $0.381^{\circ} \mathrm{C} / 10 \mathrm{a}$ and $0.438^{\circ} \mathrm{C} / 10 \mathrm{a}$, respectively. The results suggest that the minimum temperature increase played a key role in the average temperature changes in the region.

The characteristics of the relationship between area and temperature at different land-use intensity levels are summarised in Table 4 . The values of the land-use intensity were divided into three intervals (low, medium, and high). The low level was $[100,200]$, in which unused land, grassland, and water bodies were the dominant land-use types. The medium level was [200,300], in which agricultural land, water bodies, and grassland were the dominant types. The high level was $[300,400]$, in which built-up land and agricultural land were the dominant land-use types. The overall temperature exhibited an increase; however, a significant difference was observed among the three land-use intensity levels. The low-level land area decreased by $492 \mathrm{~km}^{2}$ (17.6\%), which represented the best-case land-use intensity level; however, the temperature in the low-level land increased by $0.292^{\circ} \mathrm{C}$ $(1.0 \%)$. The medium-level land area increased by $785 \mathrm{~km}^{2}$ (5.5\%), whereas the corresponding temperature increased by $0.372^{\circ} \mathrm{C}(1.2 \%)$. The high-level land area decreased by $293 \mathrm{~km}^{2}$ (9.0\%), whereas the temperature increased by $0.419^{\circ} \mathrm{C}(1.4 \%)$. Our results suggest that the increased land area of the medium level and the decreased land area of the low level were the primary causes of the temperature rise.

3.2. Response of the Temperature to Changes in the Land-Use Intensity. The study area was divided into 5,877 units, where each unit was $930 \mathrm{~m} \times 930 \mathrm{~m}$ in size. The temperature and land-use intensity within the units were analysed with spatial statistics (Figure 6). The coefficient was $-6 \times 10^{-8}$ in 2001 and $-3 \times 10^{-8}$ in 2011 . The results suggest that the sensitivity 

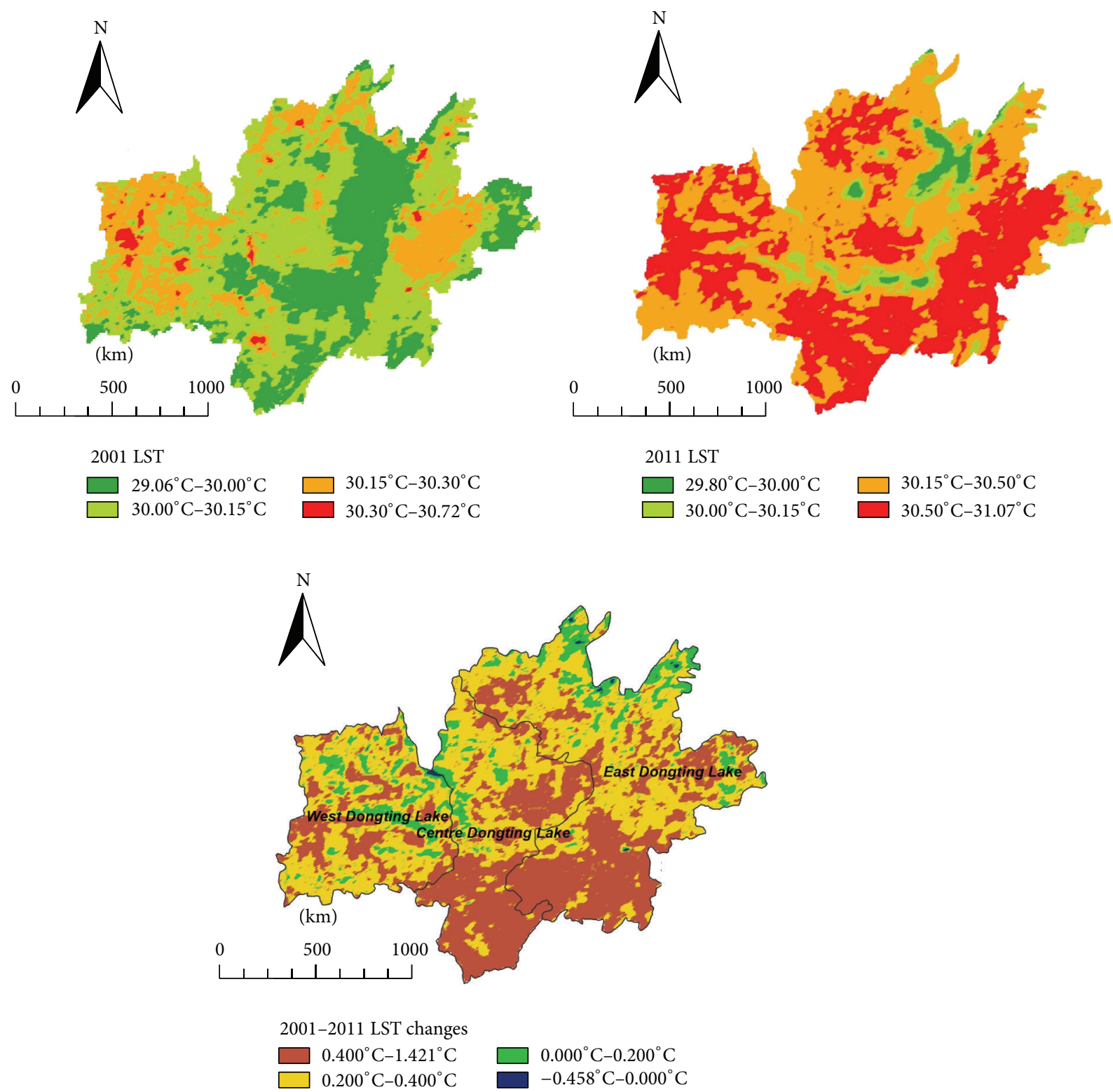

FIgURE 4: The average LSTs and changes in 2001 and 2011 (all figures depict summer: July, August, and September).

TABLE 4: Dynamic changes in the land-use intensity and temperature between 2001 and 2011.

\begin{tabular}{lcccccc}
\hline \multirow{2}{*}{ Year } & \multicolumn{2}{c}{ Low level $[100,200]$} & \multicolumn{2}{c}{ Medium level $[200,300]$} & \multicolumn{2}{c}{ High level [300, 400] } \\
& Area $\left(\mathrm{km}^{2}\right)$ & Temperature $\left({ }^{\circ} \mathrm{C}\right)$ & Area $\left(\mathrm{km}^{2}\right)$ & Temperature $\left({ }^{\circ} \mathrm{C}\right)$ & Area $\left(\mathrm{km}^{2}\right)$ & Temperature $\left({ }^{\circ} \mathrm{C}\right)$ \\
\hline 2001 & 2798 & 29.862 & 14261 & 30.066 & 3264 & 30.127 \\
2011 & 2306 & 30.154 & 15046 & 30.438 & 2971 & 30.546 \\
Change & $-\mathbf{4 9 2}$ & 0.292 & $\mathbf{7 8 5}$ & 0.372 & $-\mathbf{2 9 3}$ & 0.419 \\
Rate of change & $\mathbf{- 1 7 . 6 \%}$ & $1.0 \%$ & $\mathbf{5 . 5 \%}$ & $1.2 \%$ & $\mathbf{- 9 . 0 \%}$ & $1.4 \%$ \\
\hline
\end{tabular}

of temperature to the land-use intensity increased over the ten years. The inflection point of the curve appeared when the land-use intensity was 200 or 300 , and the warming acceleration was relatively low when the land-use intensity was $[100,200]$ or $[300,400]$; however, the temperature increased rapidly within $[200,300]$. The scatter distribution shows that the temperature rise was concentrated within $[200,300]$, which suggests that the land-use intensity within $[200,300]$ was a major influence on the temperature rise and that the land-use intensity changes due to variations in agricultural land, water bodies, and grassland were the primary causes. 


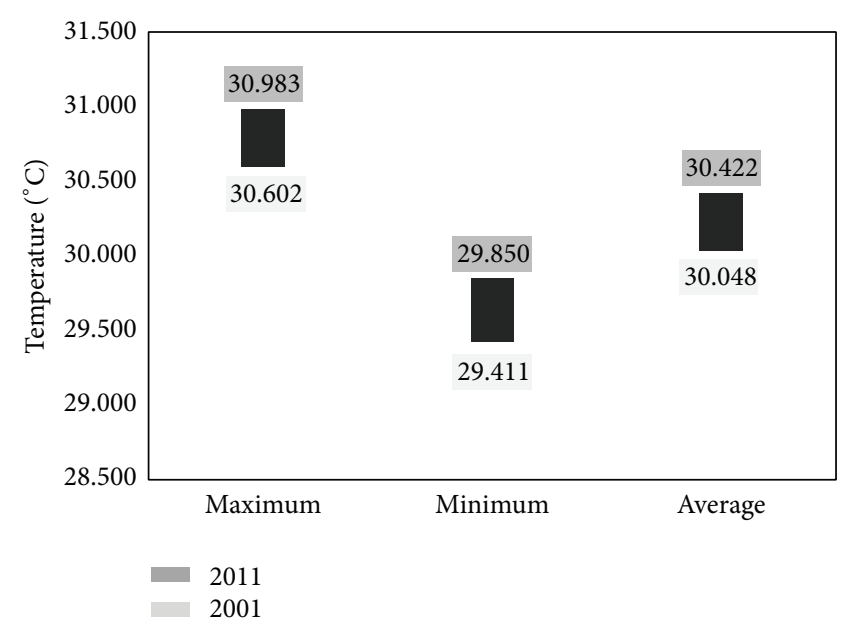

FIGURE 5: Changes in the surface temperature in the summers of 2001 and 2011.

The relationship between the temperature variations and land-use intensity over the past decade is illustrated in Figure 7. Small changes in the land-use intensity were concentrated within $[-50,50]$. Moreover, the overall land-use intensity varied slightly, while the cross-level transition was infrequent. Thus, the main influence on the temperature variation was the transition between the first and second levels or between the second and third levels. The temperature decreased with increasing land-use intensity within $[-50,50]$, indicating a negative correlation; however, when the land-use intensity was within $[-100,-50)$ and $(50,100]$, the temperature revealed a positive correlation. This finding suggests that the temperature should increase when the land-use intensity sharply changes (i.e., a hierarchical transition), for example, when the unused land-use grade changes to the urban landuse grade.

\subsection{Analysis of Influencing Factors}

3.3.1. Landscape Effects. Table 5 presents the dynamic changes in the land-use type and temperature from 2001 to 2011. The area of built-up land increased by $50 \%$, and the areas of cultivated land and water bodies increased by $4.6 \%$ and $13.6 \%$, respectively. However, forested land, grassland, and unused land areas decreased by $26 \%, 12 \%$, and $1.1 \%$, respectively. The highest to lowest temperature increases were as follows: cultivated land $\left(0.404^{\circ} \mathrm{C}\right)$, built-up land $\left(0.383^{\circ} \mathrm{C}\right)$, forested land $\left(0.352^{\circ} \mathrm{C}\right)$, water body $\left(0.349^{\circ} \mathrm{C}\right)$, unused land $\left(0.308^{\circ} \mathrm{C}\right)$, and grassland $\left(0.290^{\circ} \mathrm{C}\right)$. The temperature increase over grassland was lower than that over water bodies. The results suggest that the temperature rise primarily resulted from the expansion of built-up land or cultivated land and the reduction of forested land or grassland. Accordingly, transitions to different landscapes may lead to changes in land-use intensity. For example, when forested land or grassland was transformed to built-up or cultivated land, the land-use intensity level may have changed in conjunction with an increase in temperature.
3.3.2. Centre of Gravity Effects. The changes in the centres of gravity of temperature and land-use intensity revealed the extent of interference by human activities. From the geographical perspective, a high correlation was observed when both changes were consistent, whereas a weak correlation or no correlation was observed when they were not consistent; consistency mainly refers to changes in the same direction $[22,23] . A_{1}, B_{1}$, and $C_{1}$ are the variations in the centre of gravity of the temperature in Figure $8 . A_{2}, B_{2}$, and $C_{2}$ are the variations in the centre of gravity of the land-use intensity. $A_{1}$ and $A_{2}$ were highly consistent in terms of the direction of the change, whereas the directions of change for $B_{1}$ and $B_{2}$ and for $C_{1}$ and $C_{2}$ were inconsistent. These results suggest that a direct correlation exists between land-use intensity and temperature change in the western part of the lake, whereas the relationship was not obvious in the middle and eastern parts of the district.

These results reveal that the centre of gravity shift displayed a spatial difference that did not always vary consistently, and it could be due to other environmental factors, such as interannual and seasonal changes, global warming, and latent heat and sensible heat exchanges [24]. Therefore, the shift in the temperature's centre of gravity was affected by both land-use intensity and feedback from other environmental factors.

3.3.3. Latitudinal Effect. The latitudinal effect of temperature refers to the zonality variations from low latitudes to high latitudes. The latitude $\left(28.27^{\circ} \mathrm{N}\right.$ to $\left.29.81^{\circ} \mathrm{N}\right)$ of the region was divided into 103 equal parts, in which each part represented approximately $0.015^{\circ}$ of the latitudinal effect variation in the temperature. Figure 9 shows the correlation coefficients between the temperature and land-use intensity; the $K$ value indicates the correlation coefficients. The temperature changes ranged within $\left[0.158^{\circ} \mathrm{C}, 0.631^{\circ} \mathrm{C}\right]$, the land-use intensity changes ranged within $[-5,24]$, and the $K$ value changes ranged within $[0.581,1.414]$.

Figure 9 illustrates that a significant linear relation was detected between the temperature variations and latitude. With increasing latitude, a distinct declining trend occurred. The phenomenon suggested that the temperature variation rate was greater in high-latitude areas and that the warming trend was more notable at high altitudes. The land-use intensity variation exhibited a fluctuating rising trend with increasing latitude.

However, no significant linear relationship was observed between variations in land-use intensity and increasing latitude. These results showed that the latitudinal rules of landuse intensity variations were not obvious, and no evident increasing or decreasing trend in the intensity occurred with latitude changes. Plausibly, the temperature was influenced by several human factors, such as land-use, development measures, and economic development orientations.

Similar to the temperature variation rules, the $K$ value was characterised by zonality, which controlled the fluctuations and declines in the values. These results suggest that the temperature response range to the land-use intensity decreased gradually and that the influence of the land-use intensity on 


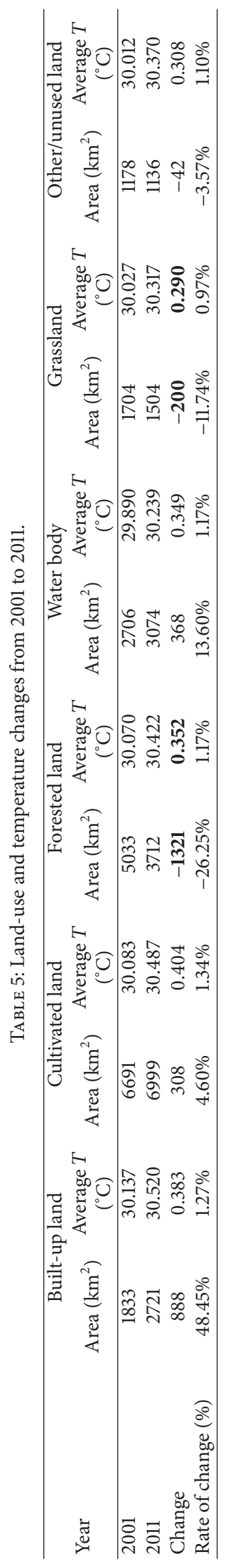




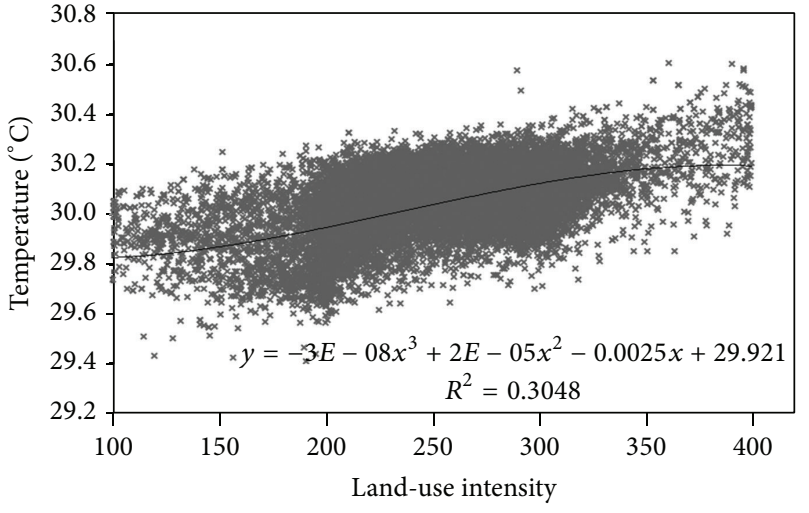

$\times 2001$

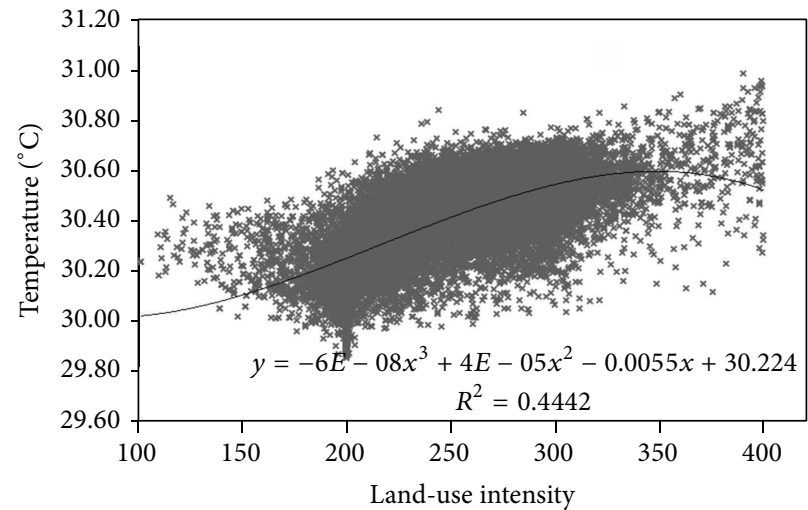

$\times 2011$

FIGURE 6: The static relationship of temperature and land-use intensity variations in 2001 and 2011.

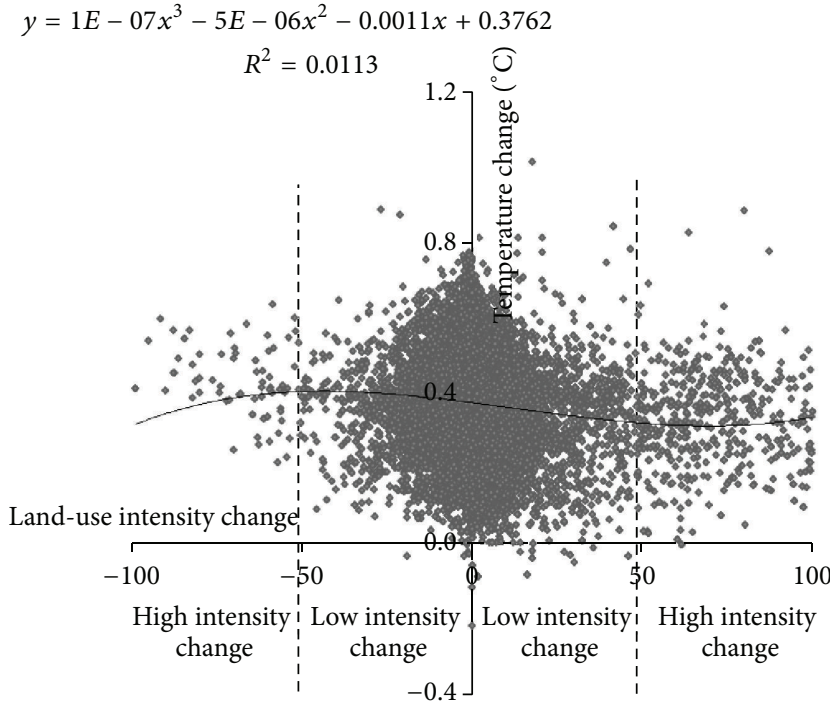

Figure 7: The dynamic relationship of temperature and land-use intensity variations over 10 years (2001-2011).

the temperature gradually declined with increasing latitude. Therefore, the temperature response to the land-use intensity was more sensitive in low-altitude areas than in high-altitude areas in the Dongting Lake District.

\section{Conclusions}

(1) The average temperature increased from $30.048^{\circ} \mathrm{C}$ to $30.422^{\circ} \mathrm{C}$ in the Dongting Lake area between 2001 and 2011. This temperature rise in the Dongting Lake District was slightly higher than the background global warming [25]. The area of built-up land and cultivated land increased by approximately $50 \%$ and $4.6 \%$, respectively, leading to an increase of $5.5 \%$ and a decrease of $9.0 \%$ in medium- and high-level land uses, respectively. These changes resulted in an increase in the land-use intensity. Built-up and

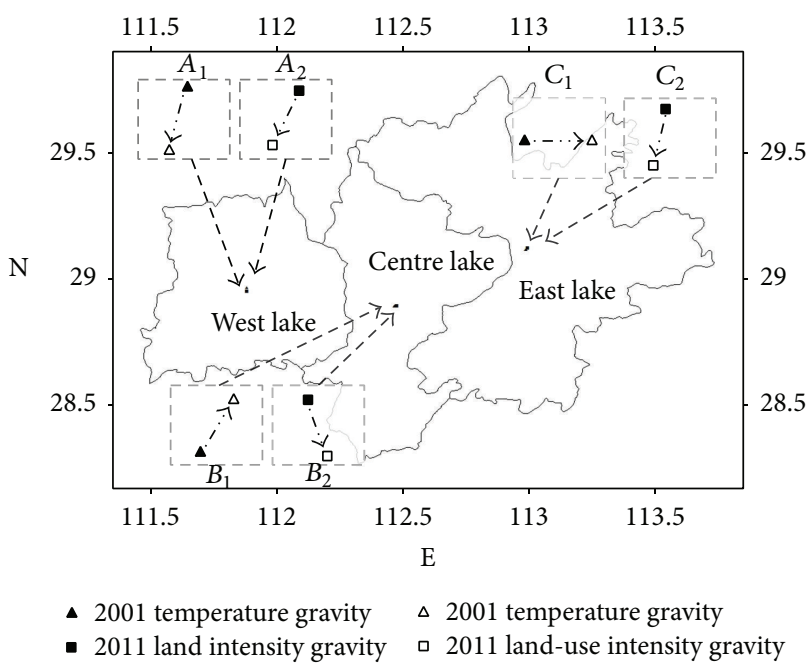

FIGURE 8: Change in the direction of the centre of gravity of the landuse intensity and temperature from 2001 to 2011.

cultivated lands were the major factors that accounted for the temperature increase. Therefore, the influence of human activities can be quantitatively expressed based on the land-use intensity.

(2) An increase in the land-use intensity generally corresponds to a temperature increase, such as the heat island effect. However, the results of this study suggest that the temperature increase was primarily caused by a change in the land-use intensity. This finding may be interpreted as land-cover change owing to a hierarchical transition and characteristics of temperature changes in the lake area. Therefore, in addition to the effects of greenhouse gases and radiative forcing, the regional land cover or land-use conversions must have enhanced the temperature change.

(3) The centre of gravity of temperature is inconsistent with the land-use intensity in most of the lake area. The shift in the temperature's centre of gravity was 


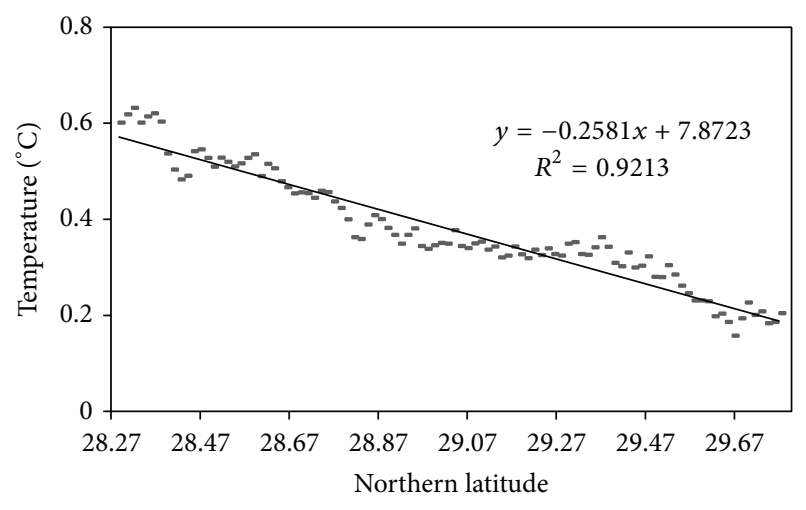

- Temperature change

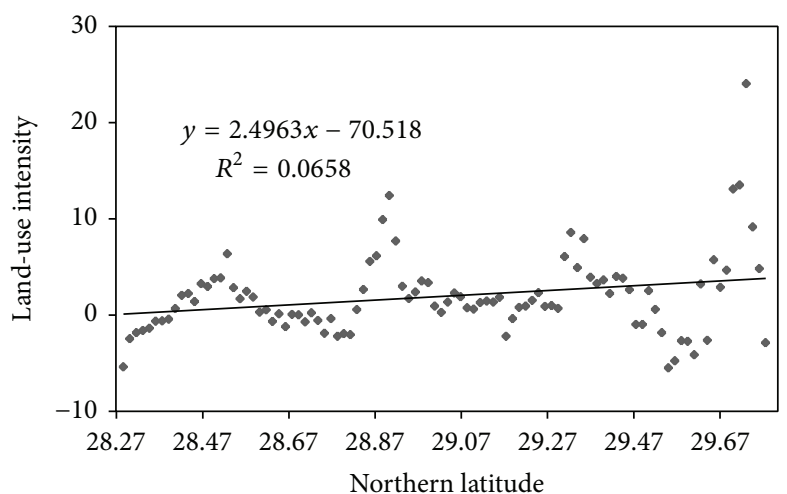

- Land-use intensity change

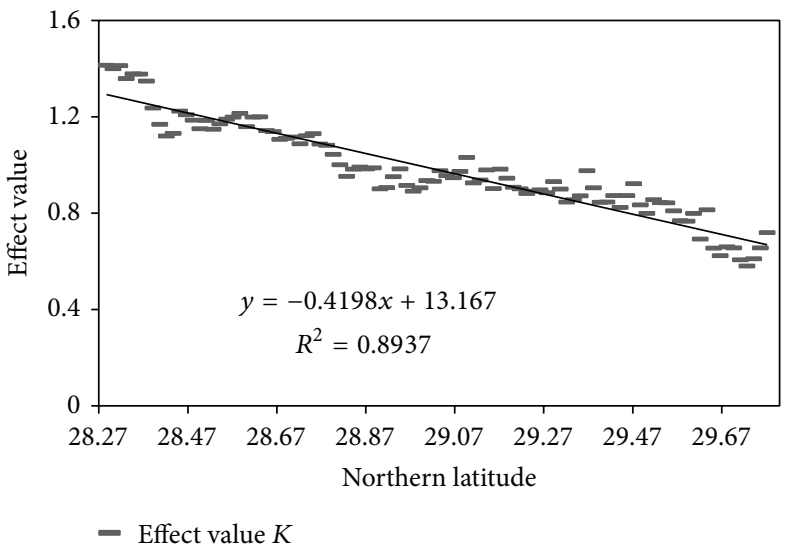

FIGURE 9: Latitudinal effects on land-use intensity and temperature from 2001 to 2011.

affected by both the land-use intensity and the external gas-water exchanges, suggesting that temperature changes in the region could be influenced by feedback from external environmental factors to an extent. For example, feedback from external environmental factors could have affected the regional atmospheric and water circulation. However, the centre of gravity of the temperature is consistent with the land-use intensity in the western region of the lake, and we can confirm that the land use and cover change strongly correlated with temperature in the west.

(4) The observed latitudinal effect showed that the extent of the temperature change gradually decreased while the land-use intensity gradually increased. Generally, the changes in temperature and land-use intensity exhibited a negative correlation. However, with increasing latitude, the degree of correlation gradually declined, suggesting that the temperature response to the land-use intensity changes was more sensitive in low-altitude areas than in high-altitude areas. In other words, the difference in the correlations between the temperature and land-use intensity did not significantly increase, possibly because the socioeconomics and urbanisation are more dominant in low-altitude areas than in high-altitude areas. Therefore, more guidance should be given to low-altitude areas.
Our study was conducted in a typical subtropical lake district between 2001 and 2011, when a rapid change in the global air temperature occurred. Moreover, the expression for land-use intensity was revised using a geographic method. This new formulation can accurately express the relationship between land-use and temperature changes and can be used to explore the relationship between land use and other climatic factors, such as rainfall, evapotranspiration, and aerosols. Because of the complexity of land-use and landcover changes, the regional temperature change is related to many factors, such as global warming caused by the greenhouse effect, topographical factors, and modulations by ENSO [26], the PDO (Pacific Decadal Oscillation) [27], and the AMO (Atlantic Multidecadal Oscillation) [28]. Our study mainly considered the single factor of land use from the perspective of macrogeography. Further studies should consider multiple environmental factors and perspectives.

\section{Conflict of Interests}

The authors declare no conflict of interests.

\section{Acknowledgments}

The authors are grateful to NASA for their support in developing their study. They thank Jiyuan Liu and Liangfu 
Chen (Chinese Academy of Sciences) for their insightful comments on the methodology. This research was funded by the National Natural Science Foundation of China (Foundation no. 41371228). They also appreciate the comments and suggestions by the anonymous reviewers.

\section{References}

[1] A. K. Mishraa, V. P. Singh, and S. K. Jain, "Impact of global warming and climate change on social development," Journal of Comparative Social Welfare, vol. 26, no. 2-3, pp. 239-260, 2010.

[2] B. L. Turner II, E. F. Lambin, and A. Reenberg, "The emergence of land change science for global environmental change and sustainability," Proceedings of the National Academy of Sciences of the United States of America, vol. 104, no. 52, pp. 20666-20671, 2007.

[3] S. Zhao, C. Peng, H. Jiang, D. Tian, X. Lei, and X. Zhou, "Land use change in Asia and the ecological consequences," Ecological Research, vol. 21, no. 6, pp. 890-896, 2006.

[4] S.-L. Lu, X.-H. Shen, and L.-J. Zou, "Land cover change in Ningbo and its surrounding area of Zhejiang Province, 19872000," Journal of Zhejiang University: Science, vol. 7, no. 4, pp. 633-640, 2006.

[5] X. Li, Z. Wang, K. Song, B. Zhang, D. Liu, and Z. Guo, "Assessment for salinized wasteland expansion and land use change using GIS and remote sensing in the west part of Northeast China," Environmental Monitoring and Assessment, vol. 131, no. 1-3, pp. 421-437, 2007.

[6] X. C. Yang, Y. L. Zhang, L. S. Liu, W. Zhang, M. J. Ding, and Z. F. Wang, "Sensitivity of surface air temperature change to land use/cover types in China," Science in China, Series D: Earth Sciences, vol. 52, no. 8, pp. 1207-1215, 2009.

[7] M. Dainese, "Impact of land use intensity and temperature on the reproductive performance of Dactylis glomerata populations in the Southeastern Alps," Plant Ecology, vol. 212, no. 4, pp. 651-661, 2011.

[8] C. P. Quine and K. Watts, "Successful de-fragmentation of woodland by planting in an agricultural landscape? An assessment based on landscape indicators," Journal of Environmental Management, vol. 90, no. 1, pp. 251-259, 2009.

[9] T. Rydberg and A. C. Haden, "Emergy evaluations of Denmark and Danish agriculture: assessing the influence of changing resource availability on the organization of agriculture and society," Agriculture, Ecosystems and Environment, vol. 117, no. 2-3, pp. 145-158, 2006.

[10] J. Liu, C. Li, and Y. Wan, "An agricultural land resource assessment study based on GIS-An example from Guiyang City," Chinese Journal of Geochemistry, vol. 21, no. 1, pp. 79-88, 2002.

[11] H. Daquan, W. Wei, D. Teqi, and L. Jinshe, "Assessment of industrial land use intensity: a case study of Beijing economictechnological development area," Chinese Geographical Science, vol. 21, no. 2, pp. 222-229, 2011.

[12] S. L. Martin, S. Cakmak, C. A. Hebbern, M.-L. Avramescu, and N. Tremblay, "Climate change and future temperaturerelated mortality in 15 Canadian cities," International Journal of Biometeorology, vol. 56, no. 4, pp. 605-619, 2012.

[13] C. Qian, Z. Yan, Z. Wu, C. Fu, and K. Tu, "Trends in temperature extremes in association with weather-intraseasonal fluctuations in Eastern China," Advances in Atmospheric Sciences, vol. 28, no. 2, pp. 297-309, 2011.
[14] G. Foster and S. Rahmstorf, "Global temperature evolution 1979-2010," Environmental Research Letters, vol. 6, no. 4, Article ID 044022, 8 pages, 2011.

[15] A. Solomon and M. Newman, "Decadal predictability of tropical indo-pacific ocean temperature trends due to anthropogenic forcing in a coupled climate model," Geophysical Research Letters, vol. 38, no. 2, Article ID L02703, 2011.

[16] S. Fall, D. Niyogi, A. Gluhovsky, R. A. Pielke, E. Kalnay, and G. Rochon, "Impacts of land use land cover on temperature trends over the continental United States: assessment using the North American Regional Reanalysis," International Journal of Climatology, vol. 30, no. 13, pp. 1980-1993, 2010.

[17] J. R. Anderson, E. E. Hardy, J. T. Roach et al., "A land use and land cover classification system for use with remote sensor data," Tech. Rep., United States Government Printing Office, 1976.

[18] B. Guindon, Y. Zhang, and C. Dillabaugh, "Landsat urban mapping based on a combined spectral-spatial methodology," Remote Sensing of Environment, vol. 92, no. 2, pp. 218-232, 2004.

[19] Z. Dafang and L. Jiyuan, "Study on the model of regional differentiation of land use degree in China," Journal of Natural Resources, vol. 12, no. 2, pp. 105-111, 1997 (Chinese).

[20] K. Mao, Z. Qin, J. Shi, and P. Gong, "The research of splitwindow algorithm on the MODIS," Geomatics and Information Science of Wuhan University, vol. 30, no. 8, pp. 703-707, 2005.

[21] J. Xu, J. Zhou, S. Luo, and H. Sun, "Study on characteristics of long-term gravity changes at Wuhan station," Chinese Science Bulletin, vol. 53, no. 13, pp. 2033-2040, 2008.

[22] S. Krätke, "A regulationist approach to regional studies," Environment and Planning A, vol. 31, no. 4, pp. 683-704, 1999.

[23] J.-M. Grether and N. A. Mathys, "Is the world's economic centre of gravity already in Asia?” Area, vol. 42, no. 1, pp. 47-50, 2010.

[24] M. Jung, M. Reichstein, H. A. Margolis et al., "Global patterns of land-atmosphere fluxes of carbon dioxide, latent heat, and sensible heat derived from eddy covariance, satellite, and meteorological observations," Journal of Geophysical Research, vol. 116, no. 3, 2011.

[25] J. Zhang, W. Dong, L. Wu, J. Wei, P. Chen, and D.-K. Lee, "Impact of land use changes on surface warming in China," Advances in Atmospheric Sciences, vol. 22, no. 3, pp. 343-348, 2005.

[26] H. Ronghui and W. Yifang, "The influence of ENSO on the summer climate change in China and its mechanism," Advances in Atmospheric Sciences, vol. 6, no. 1, pp. 21-32, 1989.

[27] H. Yang and Q. Zhang, "On the decadal and interdecadal variability in the Pacific ocean," Advances in Atmospheric Sciences, vol. 20, no. 2, pp. 173-184, 2003.

[28] M.-K. Kim and Y.-H. Kim, "Seasonal prediction of monthly precipitation in China using large-scale climate indices," Advances in Atmospheric Sciences, vol. 27, no. 1, pp. 47-59, 2010. 

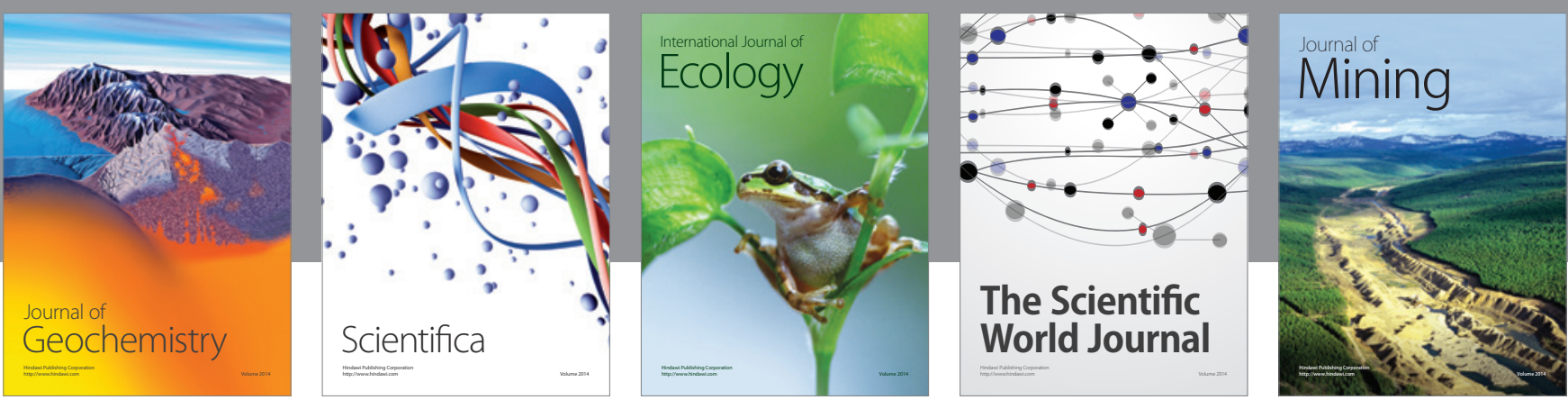

The Scientific World Journal
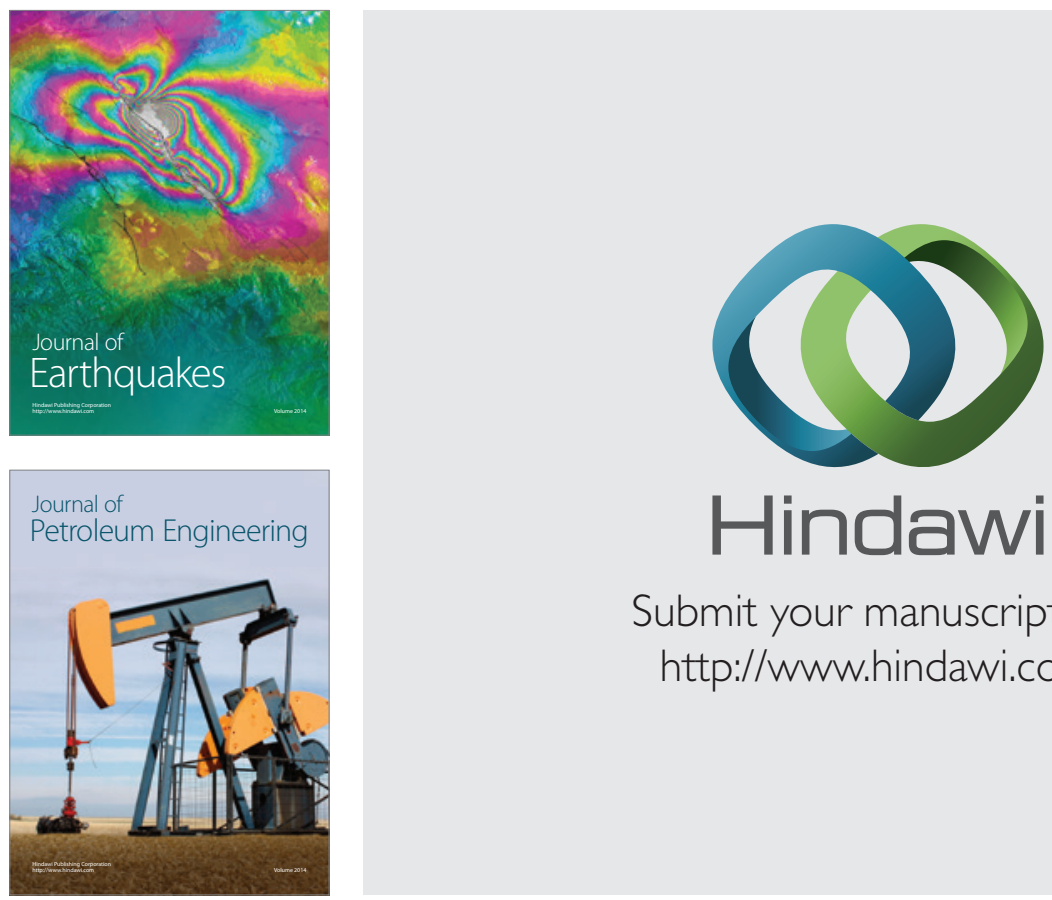

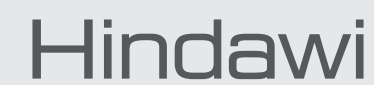

Submit your manuscripts at

http://www.hindawi.com
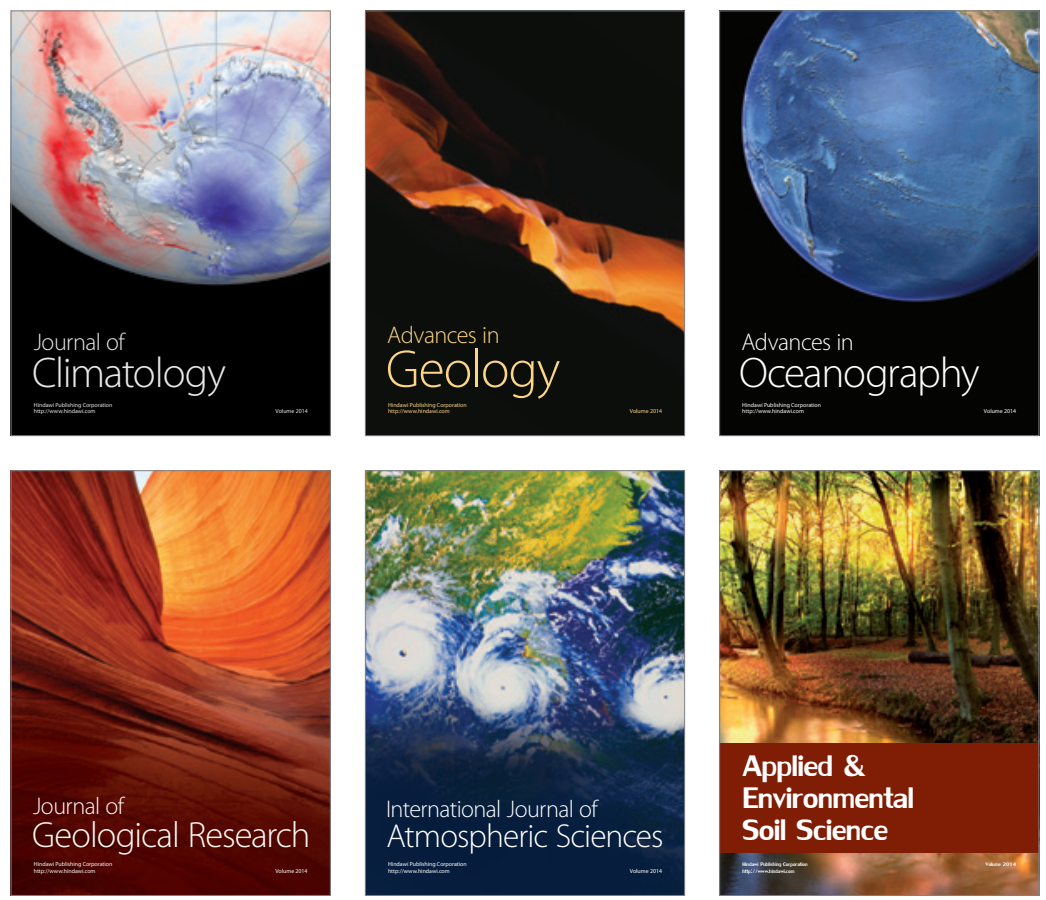
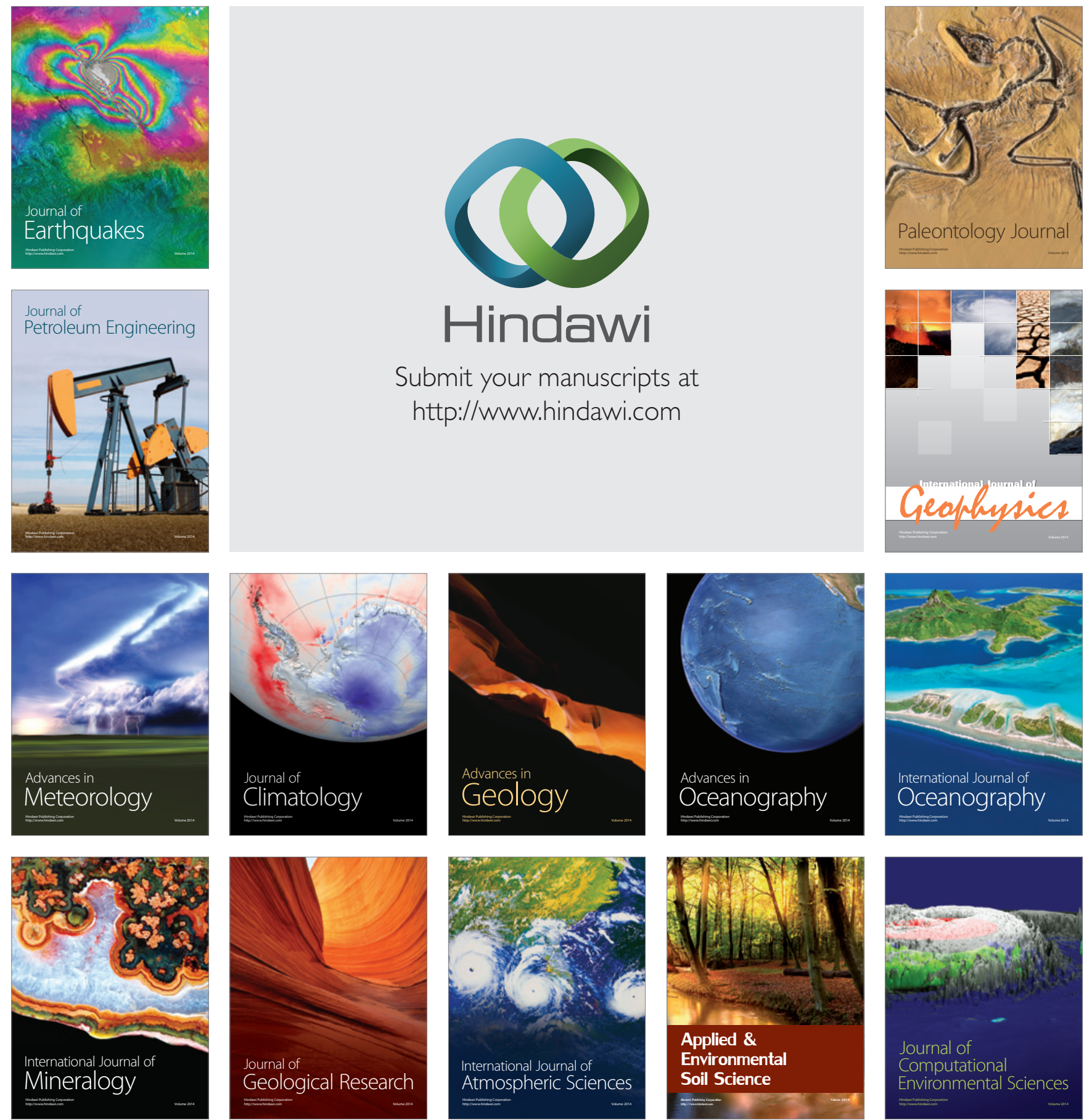